\title{
MANAGEMENT OF HUMAN CRYPTOSPORIDIOSIS IN BULGARIA, A COUNTRY WITH LOW ENDEMICITY
}

\author{
Nina D. TSVETKOVA ${ }^{1}$, Rumen N. HARIZANOV ${ }^{1 凶}$, Iskra G. RAINOVA ${ }^{1}$, \\ Iskren T. KAFTANDJIEV ${ }^{1}$, Raina B. ENIKOVA ${ }^{1}$, Nina S. YANCHEVA ${ }^{2,3}$, Kalina S. PAVLOVA ${ }^{3}$ \\ ${ }^{1}$ Department of Parasitology and Tropical Medicine, National Centre of Infectious and Parasitic Diseases, \\ Sofia, Bulgaria \\ ${ }^{2}$ AIDS Department, Specialized Hospital for Infectious and Parasitic Diseases, Sofia, Bulgaria \\ ${ }^{3}$ Department of Infectious Diseases, Parasitology and Dermato-venereology, Medical University - Varna, \\ Varna, Bulgaria
}

Received 12 Febr 2021, Accepted 01 March 2021

htips://doi.org/10.31688/ABMU.2021.56.1.02

\begin{abstract}
Introduction. Cryptosporidiosis is a protozoan infection, and in humans is most often caused by two species, Cryptosporidium parvum and C. hominis. The disease most often presents with diarrhea, and it has been defined by the World Health Organization (WHO) as a human immunodeficiency virus (HIV)-related infection. Although in Bulgaria the tests for cryptosporidiosis have been performed for almost thirty years, the disease is still insufficiently known to healthcare professionals.
\end{abstract}

The objective of the study was to determine the incidence and demographic characteristics of human cryptosporidiosis in Bulgaria for a 10-year period, from 2009 to 2018.

Material and methods. During the study period, a total of 2706 patients were examined for cryptosporidiosis by microscopic and immunochromatographic methods, of whom 2618 were immunocompetent and 88 were HIV-infected.

Results. 22 patients were diagnosed with oocysts of Cryptosporidium sp., of whom 15 were immunocompetent

\section{Résumé}

Gestion de la cryptosporidiose humaine en Bulgarie, un pays à faible endémicité

Introduction. La cryptosporidiose est une infection protozoaire, chez l'homme elle est le plus souvent causée par deux espèces - Cryptosporidium parvum et C. hominis. La maladie est le plus souvent accompagnée de diarrhée et a été définie par L'OMS comme une infection liée au VIH. Si en Bulgarie des tests de cryptosporidiose sont pratiqués depuis près de trente ans, la maladie n'est pas encore suffisamment connue des professionnels de santé.

L'objectif de cette étude est de déterminer l'incidence et certaines caractéristiques démographiques de la cryptosporidiose humaine en Bulgarie sur une période de 10 ans, de 2009 à 2018.

Matériel et méthodes. Pendant la période de l'étude, un total de 2706 patients a été examiné pour la cryptosporidiose par des méthodes microscopiques et immuno-chromatographiques, dont 2618 patients étaient immunocompétents et 88 étaient infectés par le VIH. 
and 7 immunocompromised. The average annual incidence of the disease for the studied period was 0.03 per 100000 population, and the level of this indicator is similar in some European Union countries such as Poland, Czech Republic, Latvia, Norway. The data from our study showed that the most affected were the age groups from 0 to 4 years and the female patients, and that the disease prevails in the summer months of the year.

Conclusions. In Bulgaria, human cryptosporidiosis has a low incidence rate, but in our opinion, this is mostly due to the fact that, currently, only a small number of laboratories perform tests, that hinder the determination of the actual prevalence among the population.

Keywords: cryptosporidiosis, AIDS-associated parasitic infection, microscopic diagnostic method.

\section{Abbreviations:}

$\mathrm{WHO}=$ World Health Organization

AIDS $=$ acquired immunodeficiency syndrome

HIV = Human immunodeficiency virus

NCIPD = National Centre of Infectious and Parasitic

Diseases

MZN $=$ modified Ziehl-Neelsen method

ICT $=$ immunochromatographic test

$\mathrm{n}=$ number

$E C D C=$ European Center for Disease Prevention and

Control

$\mathrm{EU}=$ European Union

$\mathrm{EEA}=$ European Economic Area

\section{INTRODUCTION}

Coccidia of the genus Cryptosporidium (phylum Apicomplexa) infect a wide range of vertebrates, including humans. To date, 26 species of cryptosporidia have been identified, and two of them are most often isolated from human clinical specimens, C. parvum and C. hominis ${ }^{1,2}$.

The infection in humans most often presents with diarrhea, which in immunocompromised patients is profuse and cholera-like. Human cryptosporidiosis has been identified by the World Health Organization (WHO) as an acquired immunodeficiency syndrome (AIDS) indicator ${ }^{3-6}$. Vulnerable groups are also premature babies, children in nursery homes, travelers to tropical countries, livestock breeders, veterinarians, zootechnicians, workers in the meat industry.

Over the years, epidemic outbreaks of cryptosporidiosis related to drinking water ${ }^{7-9}$, recreational waters and swimming pools ${ }^{10-13}$, contaminated food
Résultats. 22 patients étaient diagnostiqués avec des oocystes de Cryptosporidium sp., dont 15 étaient immunocompétents et 7 immunodéprimés. L'incidence annuelle moyenne pour la période était de 0,03 pour 100 000 habitants. Cet indicateur est à un niveau similaire à celui de certains pays de l'UE comme la Pologne, la République tchèque, la Lettonie ou la Norvège. Les données de notre étude démontrent que les groupes les plus touchés sont les enfants de 0 à 4 ans, ainsi que la population féminine, et que la maladie est plus fréquente en été.

Conclusions. En Bulgarie, la cryptosporidiose humaine a un faible taux $\mathrm{d}$ 'incidence, mais à notre avis, cela est principalement dû au fait quactuellement, seul un petit nombre de laboratoires effectuent de tels tests ce qui masque la prévalence réelle dans la population.

Mots-clés: cryptosporidiose, infection parasitaire associée au SIDA, méthode de diagnostic microscopique

consumption, animal contact and outdoor activities $^{14,15}$ have been reported from various countries all over the world. Notwithstanding that to date epidemic outbreaks of cryptosporidiosis associated with different types of water sources have not been registered in Bulgaria, a 2007 study found that out of 135 samples from different water sources, 33 (24\%) were contaminated with Cryptosporidium oocysts, with the largest number of positive samples $(n=21)$ from rivers ( $n=21$ out of 42 samples), followed by sewage water ( $n=6$ out of 12 samples), springs ( $n=5$ out of 18 samples) and water pumps ( $\mathrm{n}=1$ out of 3 samples) ${ }^{16}$.

The average incidence of cryptosporidiosis in the European Union (EU) countries for the period 2015-2017 was 3.37 per 100000 population. Among them, countries with the highest morbidity were the United Kingdom, Ireland, Germany, the Netherlands. Children aged 0-4 years were most affected (incidence of 12.5 cases per 100000 population in 2017) ${ }^{17}$. 
In Bulgaria, more systematic research on cryptosporidiosis began in the 1990s. The disease has been diagnosed among people returning from tropical countries, children from rural areas, livestock breed$\mathrm{ers}^{18,19}$. Familial cryptosporidiosis among immunocompetent individuals (husband and wife) as a result of consumption of fresh goat milk during a trip to Greece was described in $2014^{20}$. In a microscopic examination of samples from HIV-infected individuals and AIDS patients over a 15-year period (1986-2000), Cryptosporidium oocysts were found in $6(5.26 \%)$ of 114 subjects. In one patient with AIDS, both intestinal and pulmonary cryptosporidiosis was found ${ }^{21}$. In a more recent study by Yancheva et al three cases of cryptosporidiosis were diagnosed among 33 patients with HIV infection suffering from watery diarrhea and malnutrition ${ }^{22}$.

The OBJective OF THE STUDY was to conduct a retrospective analysis of the prevalence, the incidence and some demographic characteristics of cryptosporidiosis in Bulgaria over a 10-year period (2009-2018).

\section{Materials AND Methods}

\section{Study design}

The study was conducted retrospectively, from data obtained for clinical purposes and epidemiological investigations in persons with diarrheal syndrome, with or without compromised immunity, and in accordance with the Helsinki Accords and the requirements of Bulgarian legislation.

\section{Data collection}

In Bulgaria, cryptosporidiosis is a subject to mandatory notification and registration, according to Ordinance No 21/2005 on the procedure for registration, notification and reporting of communicable diseases of Ministry of Health. The annual analyses of parasitic diseases in the country, prepared by the Department of Parasitology and Tropical Medicine at the National Centre of Infectious and Parasitic Diseases (NCIPD), Sofia (Bulgaria) were used to conduct the retrospective study, for the period between January 2009 and December 2018. Also, data from the annual reports of the registered cases of parasitic diseases of the Regional Health Inspectorates (28 in number), and data of the National Centre for Public Health and Analyses for the diseases, subject to obligatory reporting and registration in the country, were used. Data from the European Union's annual summary reports on trends and sources of zoonotic diseases, zoonotic agents and foodborne outbreaks for the specified period were also used.

\section{Groups of patients}

Immunocompetent persons: in the study, there were examined fecal samples of 2618 people from different age groups (from 0 to 69 years) with diarrhea and other symptoms of the gastrointestinal tract.

Immunocompromised patients: the results include studies of 88 individuals (28 to 67 years) with HIV infection and diarrheal syndrome from the AIDS ward of the Specialized Hospital for Infectious and Parasitic Diseases in Sofia, Bulgaria. The samples were tested in the National Reference Laboratory "Diagnosis of Parasitic Diseases" in the Department of "Parasitology and Tropical Medicine" at the National Centre of Infectious and Parasitic Diseases (NCIPD). All patients included in the study were grouped by age and sex.

\section{Methods for parasitological diagnosis}

Microscopy: modified Ziehl-Neelsen (MZN) method, for presence of coccidia oocysts: a) dried fecal smears (fresh and preserved) were fixed for 3 minutes with $96^{\circ}$ methanol; b) stained with cold concentrated carbol fuchsin for 10 minutes; c) rinsed with tap water; d) differentiated with $3 \%$ acid-alcohol $(3 \% \mathrm{HCl}$ in $96^{\circ}$ ethyl alcohol); e) rinsed for $30 \mathrm{sec}$ with $0.25 \%$ malachite green; f) washed, rinsed and dried; g) microscopy was performed at 400x magnification and at $1000 \mathrm{x}$ with immersion. On a green background, the red or pink Cryptosporidium oocysts containing dark brown or dark gray intra-cystic bodies may be seen selectively ${ }^{23,24}$.

Immunochromatographic test: RIDA®QUICK Cryptosporidium/Giardia Combi Immunochromatographic Test (ICT) - the test was carried out according to the manufacturer's instructions.

\section{RESULTS}

\section{Microscopic analysis}

The study included a total of 2706 individuals (2618 immunocompetent and 88 infected with HIV) with diarrhea and/or other gastrointestinal complaints and with suspected Cryptosporidium spp. infection. Of these, 2658 individuals were examined by microscopic methods alone, 31 individuals were examined by immunochromatographic test alone, and a combination of the two tests was used in 17 subjects. Microscopic examination of fecal smears stained by MZN method revealed 22 positive samples (0.81\%) with presence of Cryptosporidium oocysts. Of the surveyed individuals, 15 (68\%) of the immunocompetent persons and 7 (32\%) of the HIV-infected patients were positive. Patients with laboratory-confirmed cryptosporidiosis were tested three times and/or 


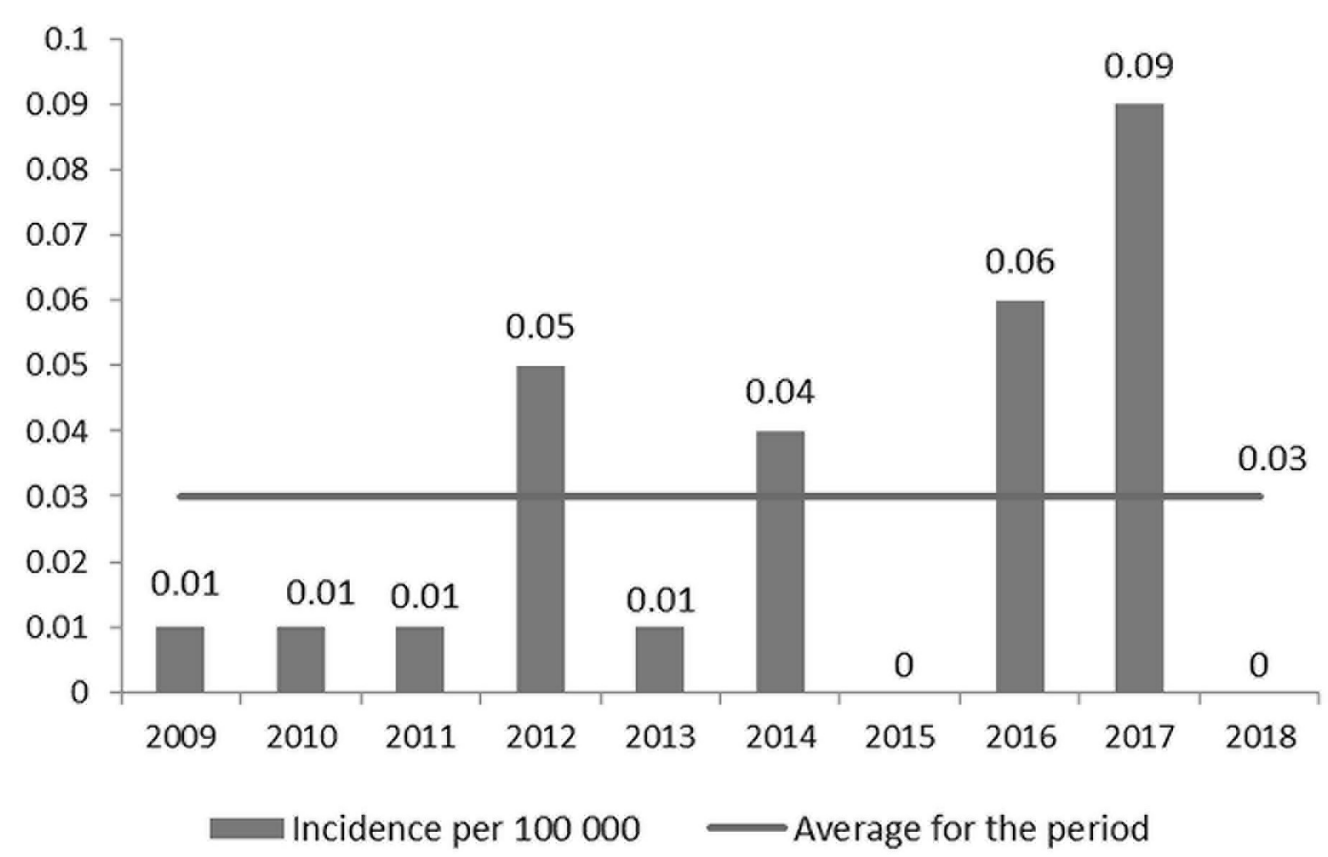

Figure 1. Annual incidence of cryptosporidiosis in Bulgaria for the period 2009-2018

until negative results were obtained after treatment in HIV-infected persons (Azithromycin $500 \mathrm{mg} /$ day for 14 days, with more severe immunosuppression for up to 21 days, in combination with antiretroviral therapy). In one of the patients with compromised immunity, a negative result was obtained after treatment and 5-fold study for a month.

\section{Immunochromatographic Test (ICT)}

A rapid immunochromatographic test for the qualitative determination of Cryptoporidium parvum/or Giardia duodenalis in stool samples (RIDA®QUICK Cryptosporidium/Giardia Combi Immunochromatographic Test (ICT), R-Biopharm, Darmstadt, Germany) was applied. The test is used mainly in the National Reference Laboratory "Diagnosis of Parasitic Diseases" and for the period of the study 48 of all patients were tested, of whom 43 were immunocompetent and $5 \mathrm{HIV}$-infected. A positive result was found in 15 (71.43\%) of them from a total of 22 persons diagnosed by MZN method. In two of the cases, in whom a combination of the two methods was applied, ICT was negative. Both cases were HIV-infected patients.

For the period of study, the highest number of immunocompetent and immunocompromised individuals who were tested for cryptosporidiosis was in $2014(\mathrm{n}=594)$, followed by those in $2016(\mathrm{n}=479)$ and $2009(n=291)$, and the lowest in $2015(n=69)$. The identified infected persons were unevenly distributed during the years of the study, with the largest number in $2017(\mathrm{n}=7)$, in 2012 and $2016(\mathrm{n}=4)$, in $2014(\mathrm{n}=3)$, in 2009, 2010, 2011 and $2013(\mathrm{n}=1)$; in 2015 and 2018 there were no patients positive for cryptosporidiosis. The average incidence for the study period was 0.03 per 100,000 population, with values of this indicator being the highest in 2017 (0.09) and the lowest in 2009 and 2010 (0.01) (Fig. 1).

\section{Age groups}

Depending on the age of the immunocompetent persons $(n=2618)$, the largest number of persons was in the age group of 5-9 years old $(n=349)$, followed by $30-34$ years $(\mathrm{n}=304), 0-4$ years $(\mathrm{n}=254), 44-44(\mathrm{n}=$ 235), 45-49 ( $\mathrm{n}=228), 35-39(\mathrm{n}=212), 25-29(\mathrm{n}=202)$, and $20-24(n=187)$. The lowest number of subjects was in the age groups of 65-69 years $(n=63), 15-19$ years $(n=45)$ and over 70 years $(n=22)$. Cryptosporidium oocysts were detected by microscopy and ICT in 15 $(0.53 \%)$ of all patients. In the age group of 0.4 years, 7 (2\% of the studied) children with cryptosporidiosis were diagnosed, in the age group $25-29$ years - 4 (2.4\%) and one positive patient in the groups of 5-9 years, $15-19$ years, $20-24$ years, and 35-39 years. The highest number of cases of cryptosporidiosis in the studied immunocompetent individuals was found in the age groups from 0 to 4 years and 25 to 29 years (Table 1 ).

Among HIV-infected people, the largest number of examined patients was in the age groups 30-34 years $(n=30), 25-29$ years $(n=13)$ and $35-39$ years $(n=12)$. Cryptosporidiosis was diagnosed in seven persons in the following age groups: from 25-29 years $(\mathrm{n}=1), 30-34$ years $(\mathrm{n}=1), 35-39$ years $(\mathrm{n}=2), 55-59$ years $(n=2)$ and 65-69 $(n=1)$. 
Table 1. Distribution by age and sex of patients examined for cryptosporidiosis and infected persons

\begin{tabular}{cccccc}
\hline $\begin{array}{c}\text { Age } \\
\text { groups }\end{array}$ & $\begin{array}{c}\text { Total exam } \\
\text { ined }\end{array}$ & $\begin{array}{c}\text { Male } \\
\text { sex }\end{array}$ & $\begin{array}{c}\text { No of } \\
\text { cases }\end{array}$ & $\begin{array}{c}\text { Female } \\
\text { sex }\end{array}$ & $\begin{array}{c}\text { No of } \\
\text { cases }\end{array}$ \\
\hline $0-4$ & 254 & 146 & & 108 & 7 \\
\hline $5-9$ & 349 & 187 & & 162 & 1 \\
\hline $10-14$ & 67 & 36 & & 31 & \\
\hline $15-19$ & 47 & 27 & & 20 & 1 \\
\hline $20-24$ & 191 & 99 & & 92 & 1 \\
\hline $25-29$ & 215 & 136 & & 79 & 5 \\
\hline $30-34$ & 334 & 176 & 1 & 158 & \\
\hline $35-39$ & 224 & 116 & 1 & 108 & 2 \\
\hline $40-44$ & 243 & 123 & & 120 & \\
\hline $45-49$ & 239 & 73 & & 166 & \\
\hline $50-54$ & 191 & 95 & & 96 & \\
\hline $55-59$ & 179 & 88 & 2 & 91 & \\
\hline $60-64$ & 86 & 45 & 1 & 41 & \\
\hline $65-69$ & 65 & 23 & & 42 & \\
\hline$>70$ & 22 & 22 & & & \\
\hline
\end{tabular}

\section{Sex}

In both immunocompetent and HIV-infected persons, the number of men tested for cryptosporidiosis was higher than in women: 1320/1298 in immunocompetent and 72/16 in HIV-infected patients. However, 17 of the patients with a proven Cryptosporidium spp. infection were females (77\%) and 5 males (23\%). Depending on the age, the largest number of positive girls and women was in the age groups $0-4$ years $(n=7), 25-29$ years $(n=5)$ and 35-39 years $(n=2)$. In the age groups 5-9, 15-19 and 20-24 years, one positive female patient was identified in each group. Two of the women in the age groups 25-29 and 35-39 years were from the group of HIV-infected. In men, those diagnosed with cryptosporidiosis were in the age groups 25-29 years $(n=1)$, $30-34$ years $(n=1), 55-59$ years $(n=2)$ and 65-69 years $(\mathrm{n}=1)$, all of whom were HIV-infected.

\section{Geographical distribution}

Studies for cryptosporidiosis between 2009 and 2018 were conducted in 6 districts of the country: Burgas, Varna, Gabrovo, Pernik, Plovdiv and Sofia-city (out of 28 districts total). The Pernik district $(1543,57.02 \%)$ had the largest number of studies of persons suspected of having cryptosporidiosis for this period, followed by the districts of Varna, Plovdiv, Sofia-city and Burgas with 494 (18.25\%), 299 (11.05\%), 264 (9.75\%) and 102 (3.77\%) persons, respectively. In Gabrovo, only one study was conducted in 2009, when 4 persons $(0.14 \%)$ were tested (Fig. 2).

The largest number of positive for cryptosporidiosis for the study period was found in Varna district in 2016 and 2017 - 8 cases among children with diarrheal syndrome aged 0 to 9 years. In 2012, in Burgas district there were diagnosed 4 cases among women with diarrheal syndrome, aged $25-29$ years. The remaining 10 cases diagnosed with cryptosporidiosis

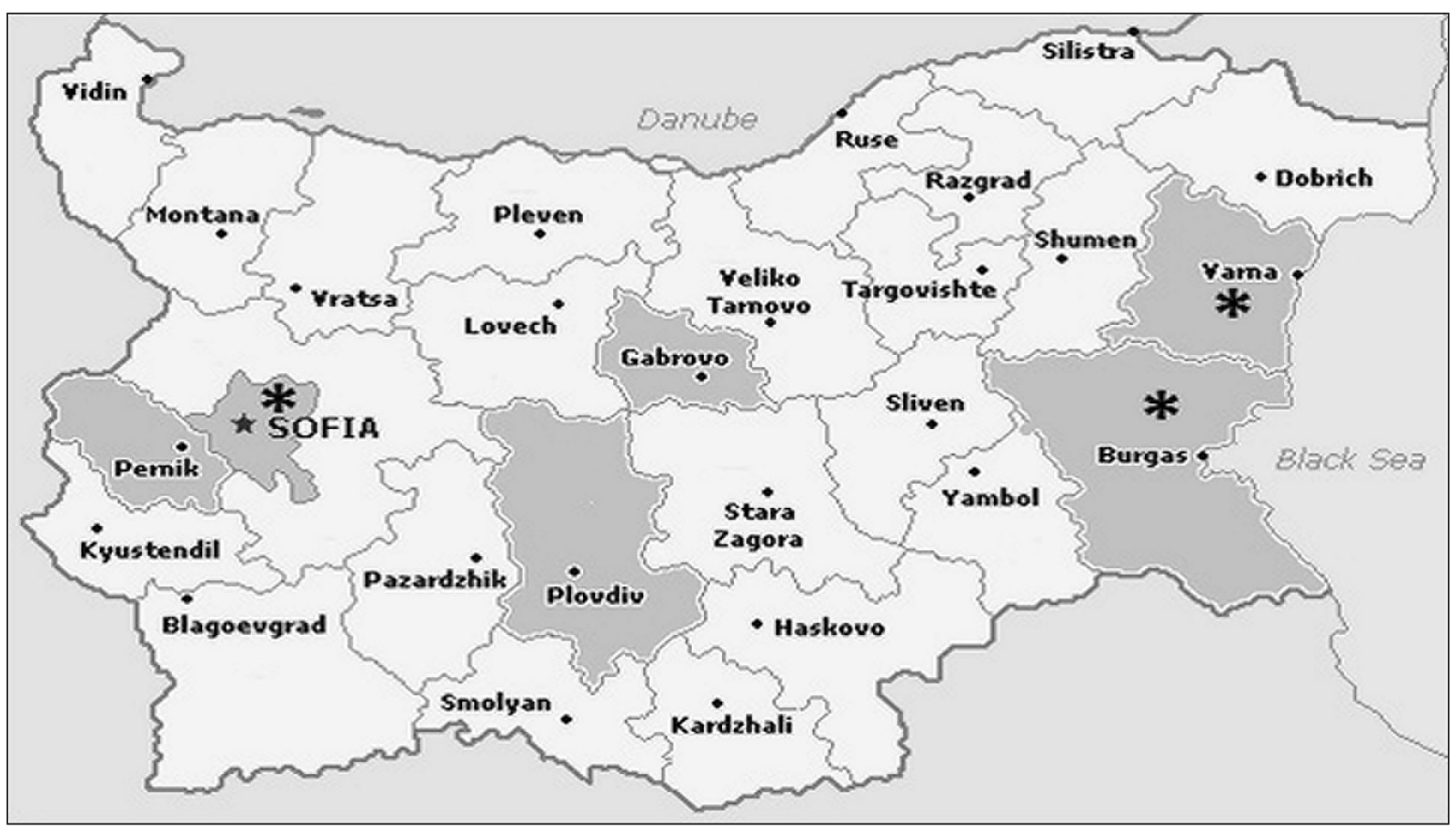

Figure 2. Administrative map of Bulgaria. Regions in which were conducted studies for cryptosporidiosis are marked in grey. Regions with reported cases of human cryptosporidiosis are marked with * 


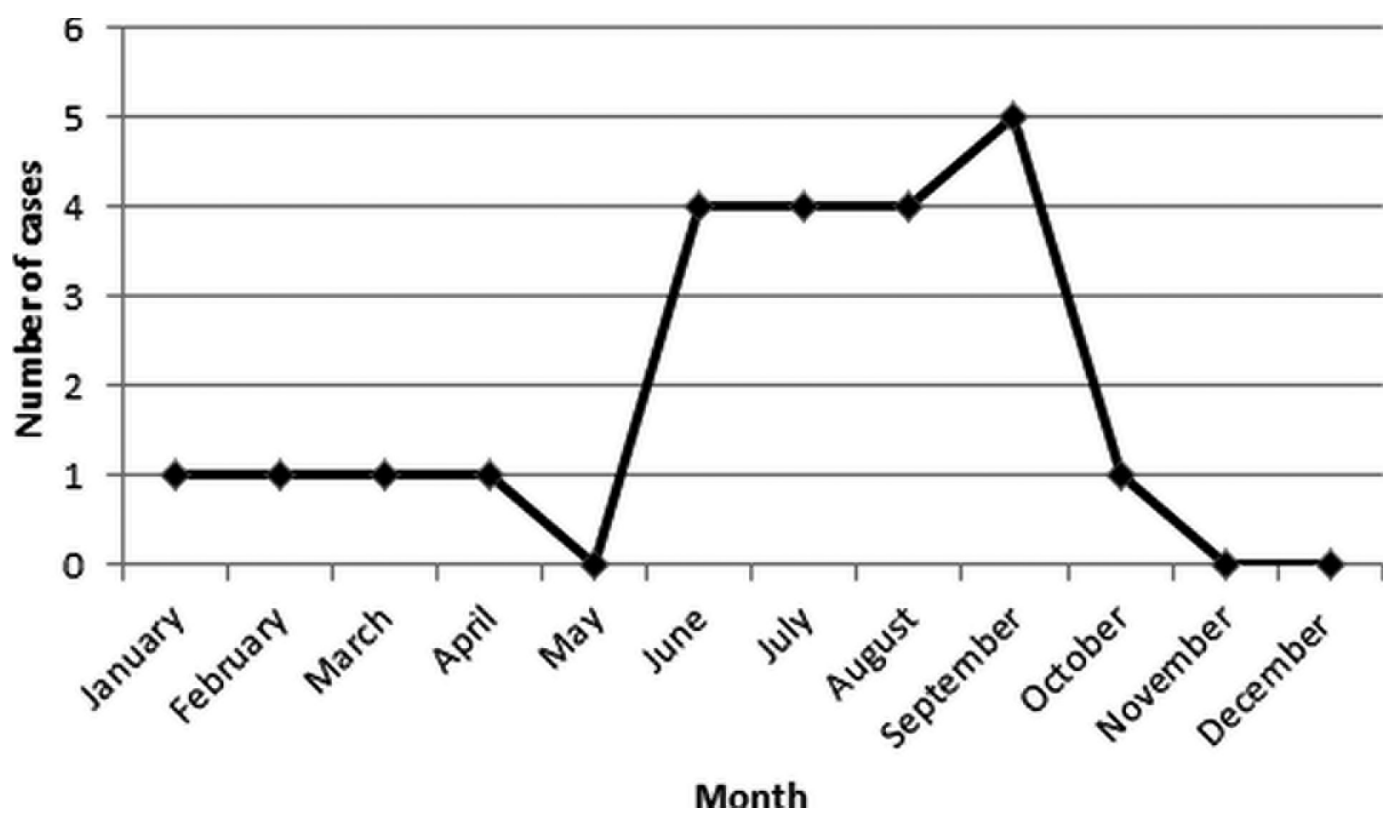

Figure 3. Seasonal distribution of reported cases of cryptosporidiosis in Bulgaria (2009-2018).

were reported by Regional Health Inspectorates of Sofia-city, one case annually: 2009, 2010, 2011, 2013 and 2016, three in 2014 and two in 2017. Seven of them were HIV-infected, and the other 3 had diarrheal syndrome. Despite the significant number of tested subjects in Pernik district for the years of the study no positive cases of cryptosporidiosis were found.

\section{Seasonality}

The seasonal distribution of confirmed $(\mathrm{n}=$ 22) cases of cryptosporidiosis for the study period was as follows: in January, February, March, April, October one case was diagnosed, 4 cases in June, July and August, 5 cases in September, while in May, November and December no case of infection with Cryptosporidium sp. was found (Fig. 3). These data outline the prevailing summer seasonality of the prevalence of cases of cryptosporidiosis in Bulgaria.

\section{Discussion}

Cryptosporidium is one of the major pathogens causing diarrhea in immunocompromised individuals and children ${ }^{25}$. The timely and accurate diagnosis and subsequent etiological treatment are crucial for a positive outcome of the disease. In Europe, as elsewhere, the severity of the disease is difficult to measure due to the lack of appropriate, standardized surveillance and control systems ${ }^{26}$. According to the Bulgarian legislation, which is harmonized with the Directives of the European Union, cryptosporidiosis in humans is a subject to mandatory registration and notification. In this regard, we believe that the data from our study show the real state of the problem with some stipulations. Due to the need for well-trained staff to perform microscopic diagnosis, targeted tests for cryptosporidiosis are performed in a few laboratories and cases of the disease may remain undiagnosed.

For the studied period, only sporadic cases of the disease were recorded in the country, with no data on epidemic outbreaks related to water or food.

The annual incidence rates range from 0.01 per 100000 (2009 and 2010) to 0.1 per 100000 (2012 and 2016), and our data are similar to those for Poland and the Czech Republic (0.01 per 100 000 for 2009 and 2010, respectively) and for Latvia and Norway (0.1 per 100000 for 2012), and Estonia (0.1 per 100000 for 2016) ${ }^{17,27}$. For the same period, the highest incidence of cryptosporidiosis was registered in Ireland - 12 per 100000 (2012 and 2017), 11.8 and 11.1 per 100000 in 2016 and 2013, respectively. According to the data from the annual epidemiological reports of the European Center for Disease Prevention and Control (ECDC) for the period 2009-2017 in the European Union (EU) and the European Economic Area (EEA) the confirmed cases of cryptosporidiosis were total of $83.308^{17,27,28}$. Bulgaria cases seem negligible (0.02\% of cases). Nevertheless, cases of the disease are registered almost annually, although exception of one case of familial cryptosporidiosis no epidemiological link has been established between them, making it difficult to determine the source of infection.

Of the registered persons with cryptosporidiosis in Bulgaria, 32\% $(n=7)$ were HIV-infected and 68\% 
$(\mathrm{n}=15)$ in patients with diarrhea syndrome, without evidence of compromised immunity. The prevalence of cryptosporidiosis among HIV-infected individuals was $7.95 \%$ and $0.57 \%$ in immunocompetent people. In this respect, our data are similar in the literature ${ }^{29}$. The distribution of cases by age shows that in persons without data of compromised immunity, the most affected was the age group of children from 0 to 4 years $(n=7.32 \%)$, and these data are identical to the literature ${ }^{26}$, while in HIV-infected persons the cases of co-infection were distributed almost evenly in the age groups from 25 to 69 years and no dominant age group was established.

The distribution by gender shows a significantly greater involvement of females (77\%) than males (23\%). It is difficult to give any explanation for this fact, but the data presented in Table 1 show that all 8 cases of cryptosporidiosis diagnosed in children and adolescents were in females. The data of Painter et al, from a study in the USA covering the period from 2010 to 2012, are similar ${ }^{30}$.

Cryptosporidiosis among humans in Bulgaria shows marked seasonality, with over $76 \%$ of all cases registered in the months of June to September ( $\mathrm{n}$ = 17). During the rest of the year, except for May, November and December, one case per month was registered.

Regarding the diagnosis of the disease, although limited in volume, the data from our study indicated a relatively good sensitivity and specificity of ICT for antigen detection. In only two cases of HIV-positive individuals the test had a false-negative result. In the remaining over $88 \%$ of the cases of cryptosporidiosis there is a complete coincidence of the results of microscopic examination and ICT. Due to their ease of implementation and lack of need for specially trained personnel, they are particularly applicable in routine practice in persons with diarrhea syndrome, but still microscopic detection of the parasite remains the main method for the diagnosis of the disease. Of course, the merits of molecular diagnostic methods should not be ruled out, but they also require special laboratory equipment and trained staff.

The data from our study are similar with those of other studies conducted in Europe and the rest of the world, which show that the epidemiological characteristics of the disease in humans caused by Cryptosporidium spp. do not differ much in terms of territory and climate conditions. Of course, the present study gives us grounds to assume that cryptosporidiosis in Bulgaria has a low endemicity, although there are suspicions of undiagnosed or misdiagnosed cases. This is probably because that the tests for the presence of Cryptosporidium oocysts are performed only in a small number of laboratories in the country, which makes it difficult to determine the actual incidence.

\section{Conclusions}

Our observations over the 10-year study period revealed an insufficient focus of general practitioners and specialists for conducting parasitological tests among people with diarrhea syndrome. In most cases, their focus is on a bacterial and/or viral infection. All these data underline the need to expand and deepen environmental research and targeted, active research of people with gastrointestinal complaints (especially children under 5 years of age, travelers to the tropics, people with compromised immune systems, veterinarians, breeders, etc.), as well as in the event of water epidemics for presence of Cryptosporidium oocysts.

\section{Author Contributions}

Conceptualization, N.T. and I.R.; methodology, R.E.; validation, N.T., R.E., K.P. and N.Y.; formal analysis, R.H. and I.R.; investigation, I.K.; data curation, N.T., R.E., N.Y. and K.P.; writing-original draft preparation, R.H., N.T., I.R.; writing-review and editing, R.H, I.R., I.K.; supervision, R.H. All the authors have read and agreed with the final version of the article.

\section{Compliance with Ethics Requirements}

"The authors declare no conflict of interest regarding this article"

"The authors declare that all the procedures and experiments of this study respect the ethical standards in the Helsinki Declaration of 1975, as revised in 2008(5), as well as the national law. Informed consent was obtained from all the patients included in the study. The study was conducted in accordance with the principles of good clinical practices (GCP) and reviewed and approved by the institutional review board (IRB) 00006384."

"No funding for this study"

\section{Acknowledgements \\ None}

\section{References}

1. Cacciò SM. Molecular epidemiology of human cryptosporidiosis. Parassitologia 2005; 47:185-192.

2. Xiao L, Feng Y. Zoonotic cryptosporidiosis. Minireview. FEMS Immunology and Medical Microbiology 2008;52:309323.

3. Forgacs $\mathrm{P}$, Tarshis $\mathrm{A}, \mathrm{Ma} \mathrm{P}$, et al. Intestinal and bronchial cryptosporidiosis in an immunodeficient homosexual man. Annals of Internal Medicine 1983;99:793-794. 
4. Pitlik SD, Fainstein V, Rios A, Guarda L, Mansell PW, Hersh EM. Cryptosporidial cholecystitis. New England Journal of Medicine 1983;308:967.

5. Ma P, Villanueva TG, Kaufman D, Gillooley JF. Respiratory cryptosporidiosis in the acquired immune deficiency syndrome. Use of modified cold Kinyoun and Hemacolor stains for rapid diagnoses. Journal of the American Medical Association 1984;252: 1298-1301.

6. Travis WD, Schmidt K, MacLowry JD, Masur H, Condron KS, Fojo AT. Respiratory cryptosporidiosis in a patient with malignant lymphoma. Report of a case and review of the literature. Archives of Pathology $\mathcal{E}$ Laboratory Medicine 1990;114:519-522.

7. Craun GF, Hubbs SA, Frost F, Calderon RL, Via SH. Waterborne outbreaks of cryptosporidiosis. Journal American Water Works Association 1998;90: 81-91.

8. Mac Kenzie WR, Hoxie NJ, Proctor ME, et al. A massive outbreak in Milwaukee of cryptosporidium infection transmitted through the public water supply. The New England Journal of Medicine 1994;33:161-167.

9. Glaberman S, Moore JE, Lowery CJ, et al. Three drinking-water-associated cryptosporidiosis outbreaks, Northern Ireland. Emerging Infectious Diseases 2002;8: 631-633.

10. MacKenzie WR, Schell WL, Blair KA, et al. Massive outbreak of waterborne cryptosporidium infection in Milwaukee, Wisconsin: recurrence of illness and risk of secondary transmission. Clinical Infectious Diseases 1995;21:57-62.

11. Van Asperen IA, Mank T, Medema GJ, et al. An outbreak of cryptosporidiosis in the Netherlands. Eurosurveillance 1996; 1:11-12.

12. Puech MC, McAnulty JM, Lesjak M, Shaw N, Heron L, Watson JM. A statewide outbreak of cryptosporidiosis in New South Wales associated with swimming at public pools. Epidemiology and Infection 2001;126:389-396.

13. Karanis P, Kourenti C, Smith H. Waterborne transmission of protozoan parasites: a worldwide review of outbreaks and lessons learnt. Journal of Water and Health 2007; 5:1-38.

14. Chalmers RM. Waterborne outbreaks of cryptosporidiosis. Annali dell'Istituto superiore di sanita. 2012;48:429-446.

15. Robertson LJ, Chalmers RM. Foodborne cryptosporidiosis: is there really more in Nordic countries? Trends in Parasitology 2013;29:3-9.

16. Tsvetkova N, Kurdova R. Detection of Cryptosporidium spp. in water samples by immunofluorescence and PCR techniques. Infectology 2007;44:139-142. (in Bulgarian)
17. European Centre for Disease Prevention and Control. Cryptosporidiosis. In: ECDC. Annual epidemiological report for 2017. Stockholm: ECDC, 2019.

18. Petrov P, Kurdova R, Filipov G, Dinev D, Yordanova D. Analysis of parasite morbidity in Bulgaria in 1992-1993 status, anti-epidemic control and prognosis. Informative Journal of NCIPD 1994; 4: 4-11. (in Bulgarian)

19. Kurdova R, Jordanova D, Vuchev D, Filipov G, Rainova I, Harizanov R. Parasitic diseases in Bulgaria. Current situation and prognosis. Informative Journal of NCIPD 2003; 3: 5-31. (in Bulgarian)

20. Eneva K, Masarlieva A. Clinically manifested family cryptosporidiosis in immunocompetent patients. Proceedings of Fourth National Symposium Exotic infectious and parasitic diseases, HIV/AIDS and co-infections 2016; 139-144. (in Bulgarian)

21. Kurdova R, Jordanova D. Opportunistic parasitoses and HIV infection in Bulgaria. Infectology 2000;37(4): 16-19 (in Bulgarian).

22. Yancheva N, Tsvetkova N, Marinova I, et al. Prevalence of intestinal parasitic infections in Bulgarian HIV-infected patients. Merit Research Journal of Medicine and Medical Sciences 2017;5:001-003.

23. Bishop PJ, Neumann G. The history of the Ziehl-Neelsen stain. Tubercle 1970; 51:196-206.

24. Henriksen SA, Pohlenz JF. Staining of cryptosporidia by a modified Ziehl-Neelsen technique. Acta Veterinaria Scandinavica 1981;22:594-596.

25. Tzipori S, Widmer G. A hundred-year retrospective on cryptosporidiosis. Trends in Parasitology 2008;24:184-189.

26. Cacciò SM, Chalmers RM. Human cryptosporidiosis in Europe. Clinical Microbiology and Infection 2016;22:471-480.

27. European Centre for Disease Prevention and Control. Annual Epidemiological Report 2013. Reporting on 2011 surveillance data and 2012 epidemic intelligence data. Stockholm: ECDC, 2013.

28. European Centre for Disease Prevention and Control. Annual epidemiological report 2014 - food-and waterborne diseases and zoonoses. Stockholm: ECDC, 2014.

29. Ahmadpour E, Safarpour H, Xiao L, et al. Cryptosporidiosis in HIV-positive patients and related risk factors: A systematic review and meta-analysis. Parasite 2020;27:27.

30. Painter JE, Gargano JW, Yoder JS, Collier SA, Hlavsa MC. Evolving epidemiology of reported cryptosporidiosis cases in the United States, 1995-2012. Epidemiology and Infection 2016;144:1792-1802. 